OPEN ACCESS

Edited by:

Jackson Cioni Bittencourt, University of São Paulo, Brazil

Reviewed by:

Guy Elston,

University of the Sunshine Coast, Australia Paolo De Girolamo, University of Naples Federico II, Italy

*Correspondence: Arthur Saniotis arthur.saniotis@knu.edu.iq

Received: 29 May 2019 Accepted: 04 December 2019

Published: 09 January 2020

Citation:

Saniotis A, Grantham JP, Kumaratilake $J$ and Henneberg $M$ (2020) Neuro-hormonal Regulation Is a Better Indicator of Human Cognitive

Abilities Than Brain Anatomy: The

Need for a New Paradigm.

Front. Neuroanat. 13:101. doi: 10.3389/fnana.2019.00101

\section{Neuro-hormonal Regulation Is a Better Indicator of Human Cognitive Abilities Than Brain Anatomy: The Need for a New Paradigm}

\author{
Arthur Saniotis $^{1,2 *}$, James P. Grantham ${ }^{2,3}$, Jaliya Kumaratilake ${ }^{2}$ and Maciej Henneberg ${ }^{2,3}$ \\ ${ }^{1}$ Department of Medical Laboratory Science, Knowledge University, Erbil, Iraq, ${ }^{2}$ Biological Anthropology and Comparative \\ Anatomy Research Unit (BACARU), Adelaide Medical School, University of Adelaide, Adelaide, SA, Australia, ${ }^{3}$ Institute \\ of Evolutionary Medicine, Faculty of Medicine, University of Zurich, Zurich, Switzerland
}

Human intelligence has been theorized since the ancient Greeks. Plato and Aristotle incorporated theories of human intelligence into their metaphysical and cosmological theories which informed the social and medical sciences for centuries. With the advent of the 20th century, human intelligence became increasingly standardized based on Intelligence Quotients (IQ). Moreover, multiple theories of human intelligence were posited on morphological features of the human brain, focusing on cranial volume and size of the pre-frontal cortex which was suggestive of superior human cognitive abilities. This article argues that fixation with anatomical features of the brain was tended to ignore the importance of neuro-hormonal regulation which is a more appropriate indicator of human cognitive abilities. The article challenges the correlation between brain size and human cognitive abilities while offering an alternate theory of human cognitive abilities which emphasizes the roles of neurotransmitters, neurotrophins, and enteric gut microbiome (EGM) regulation.

\footnotetext{
Keywords: intelligence quotient (IQ), brain size evolution, dopamine, serotoinin, neurotrophin, enteric gut microbiome
}

\section{BIGGER IS NOT NECESSARILY BETTER: HISTORICAL ROOTS}

The historic understanding that intelligent individuals are "big-brained" has permeated throughout modern science and prompted subsequent research to support this view. The noted neuroanatomist Paul Broca (1924-1880) suggested that bigger brain size correlated with higher intelligence and that Europeans had larger brains than Africans (Broca, 1861). Such ideas influenced scientific and political establishments during the period (Morton, 1849; Darwin, 1871).

Moreover, Galton (1888) demonstrated that university students with larger cranial measurements had an overall better academic performance. Subsequent investigations in the 20th century, in which more sophisticated methods were used to measure brain size and evaluate intelligence seemed to support the findings of Galton (Tan et al., 1999). However, a meta-analysis conducted in 1996 found that correlations between the various measures of 
brain size and intelligence scores ranged between 0.08 and 0.35, with an unweighted mean of 0.21 (Rushton and Ankney, 1996). Importantly, this unweighted correlation coefficient of 0.21 indicates that less than $5 \%$ of all variance in intelligence can be attributed to brain size. These findings have led many researchers to question whether there is a significant relationship between cranial volume and intelligence (Gould, 1996). Moreover, Intelligence Quotients (IQ) comprises knowledge and skills acquired through informal and formal education. Education varies depending on the socioeconomic circumstances of individuals and communities. Stature varies with socioeconomic conditions, and there is a correlation between stature and brain size. Thus, brain size/IQ covariance may be an artifact of living conditions and education (Olivier et al., 1970; Henneberg et al., 1985). Average brain sizes of females are approximately $150 \mathrm{ml}$ (one standard deviation) smaller than those of males, yet there is no concomitant female/male difference in mental aptitude test scores (Henneberg et al., 1985).

These views are substantiated by numerous studies conducted that fail to show a statistically significant relationship between head size and scores on intelligence testing (Henneberg et al., 1985; Saniotis et al., 2014). The phenomenon of "publication bias" has likely prevented more publications of the negative finding of no relationship between brain size and intelligence, as authors who find no correlation tend to think that they have nothing to report. Reservations surrounding the link between brain size and intelligence are further supported by a number of contentions regarding the possibility of spurious correlations. These include body height, which is known to correlate with both cranial capacity and intelligence (Henneberg, 1998).

\section{HYPOTHESIS}

Although a general positive correlation between brain sizes/encephalizations and behavioral complexity exists when comparisons are made across members of various animal orders, such regularities do not seem to work in both species and individuals (Lefebvre, 2013). These inconsistencies further illustrate the limitations of an anatomical explanation in describing sophisticated phenomena, such as human cognitive abilities. The hypothesis on the positive link between intelligence and brain size in hominins has been already falsified by numerous findings. Therefore, a new hypothesis is needed. There needs to be increased attention paid to neurohormonal regulation in influencing human cognitive abilities. We offer an alternate theory of human cognitive abilities which emphasizes the roles of neurotransmitters/neurotrophins and enteric gut microbiome (EGM) regulation.

\section{BRAIN EVOLUTION AND CONCEPTUAL CHALLENGES}

Human brain evolution has for decades been informed by an essentialist approach in describing biological variation. A study of the literature reveals the maintenance of essentialist ideas in understanding brain evolution, with a principal idea of brain volume being the underlying signifier of intelligence being incorrect (Saniotis and Henneberg, 2013a).

Much of the fascination into human brain size has tended to focus on the human frontal lobe. A probable reason for this persistence with frontal lobe volume has been in order to verify the superiority of human cognitive abilities over non-human animals. Since the frontal lobe (more specifically the prefrontal neocortex) regulates executive functions and higherorder cognition it is reasonable that scientists focussed on this area. Although there has been considerable frontal lobe expansion in hominins from the early Paleolithic period, this issue has not been resolved and remains unclear (Barton and Venditti, 2013).

Consequently, two schools of thought have arisen relating to whether human prefrontal cortex (PFC) is predictably larger for a primate brain (Blinkov and Glezer, 1968; Passingham, 1973; McBride et al., 1999; Sherwood et al., 2005; Navarrete et al., 2011), or is not predictably larger for a primate brain (Brodmann, 1913; Semendeferi et al., 2002; Smaers et al., 2011; Barton and Venditti, 2013; Hoffmann, 2013). Some theorists cite lack of consistency in measuring differences in relation to white and gray matter volume in the PFC (Smaers et al., 2011), total frontal cortex size (Semendeferi et al., 2002), or inappropriate measuring methods for this lack of consensus (Elston and Garey, 2009; Barton and Venditti, 2013). For example, dimensions of various cerebral structures have altered at dissimilar levels during the evolution of body size and brain (Barton and Harvey, 2000; Barton and Venditti, 2013). Furthermore, hominin cranial material tends to be fragmentary and open to speculations. A methodological problem lies in the making of endocasts of hominin braincases. Henneberg (1998) claims that while braincase volume can be larger in hominin specimens than the tangible brain, it is the endocast that is used as an indicator of the actual brain size.

Another issue relates to a lack of vigorous research into the cytoarchitecture of the brain. An understanding into the cytoarchitecture of the PFC such as the number of neurons and cortical networks in the granular layer of the PFC (gPFC; Barton and Venditti, 2013), has implications on how intelligence is measured (Elston and Garey, 2009).

Unfortunately, the laborious nature of comparing the PFC across species, as well as, lack of scientific funding detract from a further scientific investigation in this important area of brain evolution (Elston and Garey, 2009; Passingham and Smaers, 2014).

Furthermore, in keeping with the hypothesis of brain size contributing to improved intelligence, males, with their firmly established average larger cranial capacity, should demonstrate greater intellectual aptitude. However, the sexual dimorphism of mental ability, although proposed, remains inconclusive. Perhaps the biggest detraction from considering brain volume predictive of intelligence is the weakness of the correlation. Even when accepting the findings of the most ardent supporters of brain size informing intelligence, only a modest influence can be claimed. This leads us to the conclusion that variation in mental aptitude must be primarily a result of the variation in 
brain physiology, especially biochemical variation in substances facilitating neuronal communication (Henneberg et al., 1985). This is further demonstrated in a recent study that found that individuals possessing higher mental performance have less neuronal arborization and density of dendrites. The study suggests that higher intelligence is predicated on less but better organized and efficient neurons.

\section{THE DECREASE IN HUMAN BRAIN VOLUME}

With the broader scientific acceptance that larger brains convey greater mental capacity, numerous studies have concentrated on showing a postulated link between an evolutionary enlargement of the brain and increased behavioral complexity.

Undoubtedly, there could be a coincidence between the increase in the size of the brain and the improvement in markers of social intelligence over the last 3 million years (De Miguel and Henneberg, 2001), though it is not obvious which is the cause and which the effect. However, recent work has shown that an increase in hominin brain size parallels increasing in hominin body size (Henneberg, 1998; Henneberg and Saniotis, 2009; Saniotis and Henneberg, 2011). This infers that these changes in brain volume may be a result of increasing body size rather than a reflection of increasing intelligence. The increase in body size itself may be a result of increasingly better management of resources by hominins (Olney et al., 2015) allowing growth in body size. Better resource management may be a result of improved mental abilities due to changes in neurohormonal regulation and brain physiology.

Furthermore, the concept of a larger brain leading to better cultural and technological performance did not hold true for the Holocene (last 10,000 years), when the average human brain size decreased by approximately 10\% (100-150 ml, that is one standard deviation; Henneberg, 1988; Brown, 1992; Ruff et al., 1997). This is the period during which time civilizations developed, written language and formal mathematics were introduced and sciences and technologies progressed (Henneberg and Steyn, 1993).

\section{HUMAN AND ANIMAL BRAIN: WHAT THE RESEARCH SHOWS}

Behavioral differences between apes and humans and advances in the history of human evolution can be adduced to superior chemical regulation of brain function rather than larger brain size (see Figure 1).

There is evidence to support this postulation, with humans demonstrating 3-fold higher thyroid hormone activity and more developed dopaminergic system in the pre-frontal cortex in comparison to other primates (Previc, 1999; Gagneux et al., 2001). While Gagneux et al. (2001) postulate a possible link between lower T3 and T4 in chimpanzees with hypothyroidism and associations with cretinism, this does not explain how chimpanzees in captivity have consistently been shown to possess far better working memory of numbers than humans (Inoue

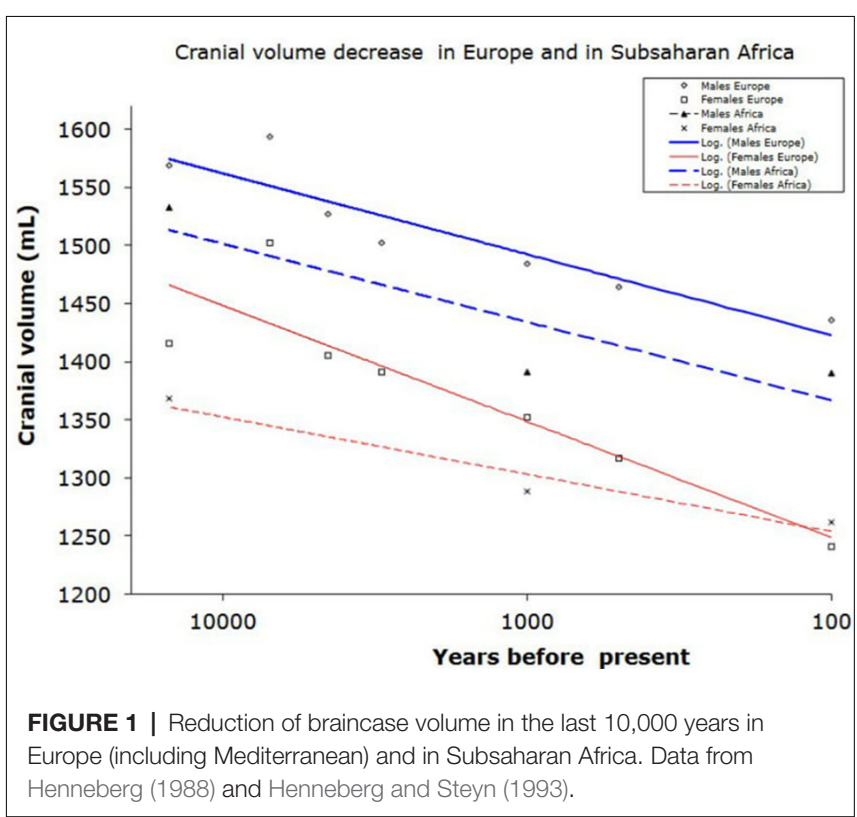

and Matsuzawa, 2007). The hypothesis of superior chemical brain regulation leading to better cognition has not yet been falsified. Contrariwise, the wide use of substances that alter brain functions in humans shows a number of positive and negative influences upon cognitive abilities.

A considerable body of evidence that detracts from the significance of brain volume in relation to intelligence can be derived from the broader animal kingdom. Measuring intelligence across different species is an elusive exercise and fraught with multiple problems. One such problem is the misnomer of the uniformity of the cerebral cortex in mammalian species (Elston and Garey, 2009). This prevalent viewpoint assumes that mammals share the same cortical organization (Kolb and Tees, 2000; Jerison, 2001; Elston and Garey, 2009). However, a counter-argument notes that acceptance of the cortical uniformity hypothesis refutes heterogeneity in cortical microstructures (pyramidal neurons in the granular level of the PFC) at both inter and intra levels in mammals (Elston, 2003; Elston et al., 2006). Fuster (2001) points out the fallacy of one specific function attributed to the PFC while ignoring other complementary functions.

It has been shown that pyramidal cells are not only integral to basic cortical synaptic excitation and inter-areal and intraareal projections but also reveal remarkable heterogeneity in the primate cerebral cortex (Elston et al., 2011). The variation in pyramidal cells in the cortices in different species demands a less essentialistic approach (Kasper et al., 1994; Gao and Zheng, 2004; Spruston, 2008). At this stage, our understanding of neuronal diversity in all of its complexity is still underdeveloped.

Most of the phylogenetic analysis of pyramidal cells have derived from the primary sensory cortices of laboratory mice (Luebke, 2017). Consequently, our understanding of pyramidal cell heterogeneity from a large range of mammalian species is lacking. For example, the dynamic processes of mouse 
cortical neurons (consisting of multimodal FC and V1 that are low in their dynamic range) are suitable for quick synaptic communication (Luebke, 2017). However, the neocortex of mice is less differentiated and less complex than the cortex of rhesus monkeys. The greater complexity of the latter requires more functionally marked cortical areas that are qualitatively different in their levels of filtering, excitation and input integration than mice cortical areas (Barbas, 2015; Luebke, 2017).

For the purposes of discussion, animal intelligence has been broadly defined as the ability to produce flexible responses to challenges posed by the environment and by other individuals. It is generally accepted that larger animals possess larger brains and many of these species are associated with higher intelligence (Jerison, 1973). However, mammals possess a large range of brain sizes and body sizes of approximately "eight orders of magnitude" (Dicke and Roth, 2016). Generally speaking, both mammal and avians have brains that are approximately 10 times larger than those of vertebrate fish, amphibians and reptiles of equivalent body mass (Lefebvre, 2012). Yet, bird cortices are smooth and very small while birds' behaviors match those of many mammals and humans (e.g., language communication). Most of the complex neuronal processing in birds' brains occurs in subcortical structures, especially in the dorsal ventricular ridge that may perform the same functions as the mammalian neocortex (Font et al., 2019). This clearly indicates that the same phenotypic characteristics of "intelligent" behaviors can be facilitated by different parts of the brain with different interconnections. The size or localization of brain structures underlying behaviors is of little consequence.

Although primate cortical cell densities are comparatively higher than those found in cetaceans and elephants, this does not explain why primate brains are superior in relation to intelligence. Neuronal densities in the human cortex are much lower than those in great apes (Haug, 1987) While there is a strong general correlation between brain size and body size, there is no such correlation among sub-samples of closely related species where the range of unexplained variation of brain/body size relationships is large (Dicke and Roth, 2016). This becomes evident when comparing relative brain size between animal species even after correcting for body size. Although parrots (psittacids) possess larger brain volume than corvids, both show high intelligence and have the ability to manipulate objects as tools (Dicke and Roth, 2016). Similarly, dolphins possess a bigger "corrected value" brain size than chimpanzees and gorillas but are considered by some theorists as being less intelligent than Pongidae (Manger, 2013; Güntürkün, 2014; Dicke and Roth, 2016).

Both the smallest and the largest mammals (shrews, mice, elephants, and whales) have large repertoires of flexible behaviors. Despite these factors, a general association between the encephalization quotient and complex behavior among mammals has been postulated (Geary, 2005). However; complications are encountered when stepping outside the mammalian class. Birds generally possess encephalization coefficients (Armstrong and Bergeron, 1985), and cortical volumes that are inferior to those of most mammals
(Lefebvre, 2013; Roth, 2013). Despite this, they display enormous behavioral complexities, including the use of tools, construction of complex nests, and "intelligent" conversation in human languages. A recent study concludes that three species of Corvidae (New Caledonian crows, jackdaws, ravens) have the motor regulation equivalent to great apes despite having much smaller brains (Kabadayi et al., 2016; Figure 2).

It has also been shown that ravens (Corvus corax) recognize what conspecifics can be accessed or not-a rudimentary "Theory of Mind" (Emery and Clayton, 2001; Dally et al., 2006; Bugnyar et al., 2016). So why are some avian species so smart? It seems that the avian brain has undergone convergent evolution where it does not follow the six-layered PFC as found in mammals (Emery and Clayton, 2005). Instead, the avian homolog of the PFC could be the caudolateral nidopallium. This area shares similarities with a mammalian prefrontal cortical function such as delayed task response, working memory and reversal learning (Emery and Clayton, 2005). The architecture of the avian brain reveals how nature has been able to evolve intelligent animals with small brain volume when compared to non-human and human primates.

\section{NEUROTRANSMITTERS AND NEUROTROPHINS IN HUMAN BRAIN EVOLUTION}

\section{Dopamine}

There is increasing evidence to support the importance of neurotransmitter regulation and its impact on brain development and intelligence during hominin evolution (Raghanti et al., 2010). Various authors have described the role of DA in human brain evolution (Previc, 2002, 2009; Raghanti et al., 2010). DAergic innervation is involved in motor planning, and higher-order cognitive abilities including reasoning, language comprehension, future projection and general intelligence (Raghanti et al., 2010).

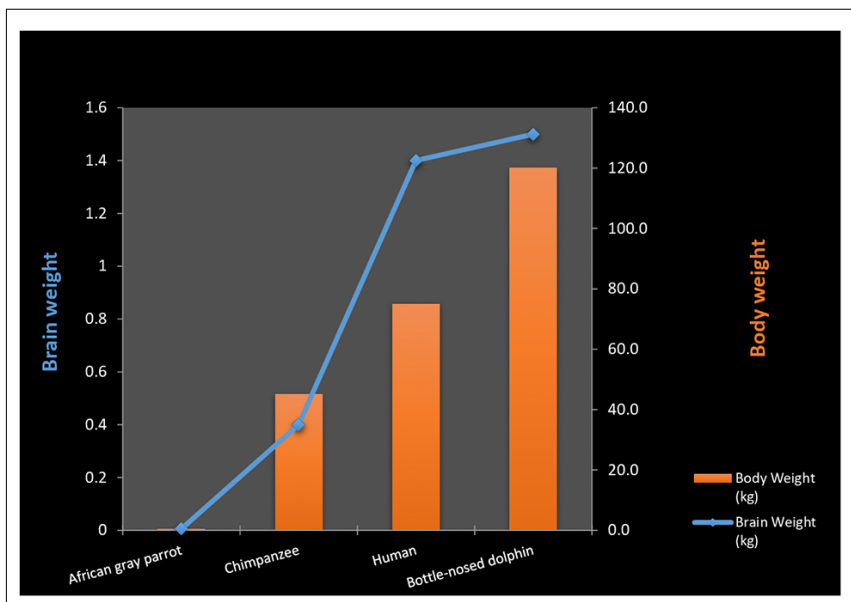

FIGURE 2 | Body weight to brain ratio in various animal species. 
Humans and other primates receive DA through many cortical regions. The human brain not only has increased DAergic efferent density in layers III, IV, and VI PFC areas, but has more DAergic input to the PFC regions than other primates (i.e., chimpanzees, macaques; Akil et al., 1999).

The idea of neurohormonal regulation of DA acting as a factor that guided primate evolution has been investigated (Previc, 2009). The increase in DA concentrations has paralleled increases in the size of the human neocortex (Raghanti et al., 2008). Previc formulated the DA hypothesis. This hypothesis is posited on climatic changes, which occurred during the Pliocene/Pleistocene transitions ( $\sim 2 \mathrm{Ma}$ ago) leading to changes in hominin morphology that were positively selected for endurance hunting/foraging over a large ecological range (Previc, 2009). Thermal stress resulting from endurance hunting triggered thermoregulatory mechanisms involving DA (Roelands and Meeusen, 2010). This idea concurs with Hoffmann (2013) who suggested that DAergic dependent cognitive faculties are an exaptation of DA mediated thermo-regulatory function. Previc's theory is supported by recent findings which indicated that a variation of the gene cluster in chromosome 11 (i.e., that converts fatty acid desaturase cluster or FADS) occurred $\sim 85 \mathrm{ka}$, a time when hominins may have increased their intake of omega $3 \mathrm{DHA}$ sea food, thereby influencing human brain evolution (Mathias et al., 2012). Paleoanthropological findings confirm that ancestral hominins in Pinnacle Point, South Africa ( 160 ka; Marean et al., 2007), Eritrea ( 125 ka; Walter et al., 2000), and the South African coastline ( $\sim 100 \mathrm{ka}$; Broadhurst et al., 2002) included shellfish in their diet.

Previc argues that an increase in DHA may have consequently increased the levels of DA and thyroid hormone, thyroxine (T4), which is necessary for expanding human cognition (i.e., working memory, language fluency, and creativity). Interestingly, it is known that humans possess significantly higher concentrations of T4 than chimpanzees, as discussed earlier. This hormone is responsible for converting tyrosine to L-dopa (DA precursor). Numerous studies have confirmed that deficiencies in DA are commonly associated with neuro-cognito-behavioral impairments in humans (Previc, 2002; Brisch et al., 2014; see Figure 3).

According to Previc's thesis DA increase in the last 9,000 years was approximately the same as during the last 8 million years. It is interesting that exponential increase in DA happened during the early Neolithic period (10 ka ago)-when there was a transition from foraging/hunting to agricultural societies/animal husbandry. It is also evident that DA in Homo has been steadily rising since the early Neolithic period to the present accompanying the reduction of brain size.

\section{Neurotrophins}

Several studies have also linked neurotrophins with increasing cognitive abilities during human evolution (Raichlen and Polk, 2013). Raichlen and Polk (2013) argue that increasing physical activity levels (PAL; i.e., persistent hunting) in $H$. erectus onwards upregulated neurotrophin and growth factors prodution, such as brain derived neurotrophic factor

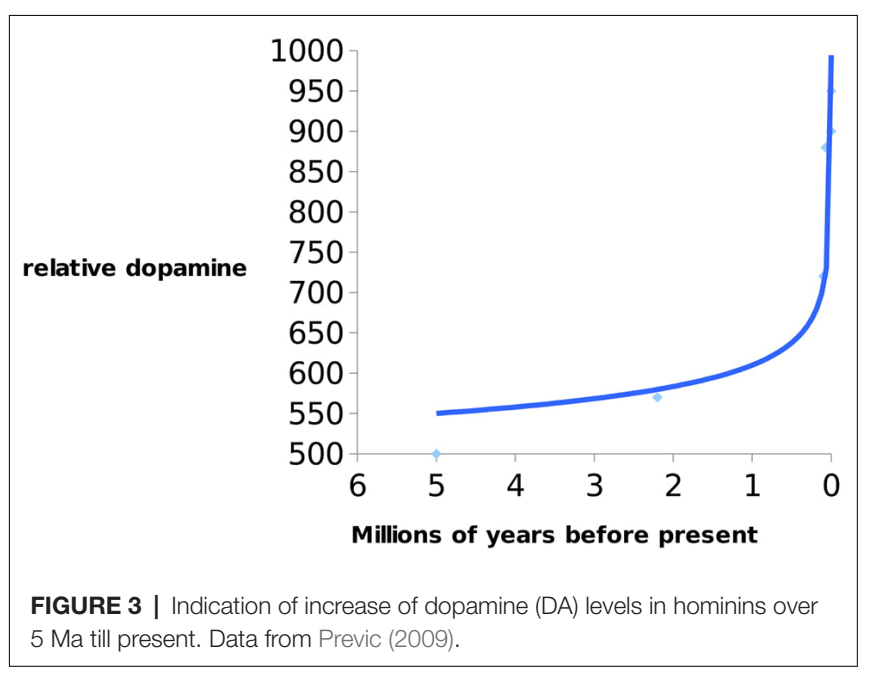

(BDNF), vascular endothelial growth factor (VEGF), and Insulin like growth factor (IGF). This upregulation led to increasing hippocampal neurogenesis, planning abilities, spatial memory and neuroplasticity (Mattson, 2012; Noakes and Spedding, 2012; Raichlen and Polk, 2013). This transition to higher PAL, may, therefore, have accelerated human cognitive abilities. Indeed, this transition to higher PAL would have come at a time of other socio-biological developments in Homo such as extended adolescent period, increasing reliance on technology for food procurement and security and increasing social complexity (Saniotis and Henneberg, 2013b).

Therefore, BDNF may have been positively selected due to its neurotrophic and neurogenetic functions. Such probable positive selection may explain the correlation between exercise and BDNF production, and why exercise is important in neurogenesis in the hippocampal dentate gyrus, and enhanced cognitive performance (Saniotis and Henneberg, 2013b). In one animal model, mice were given an extensive running regime in order to ascertain the correlation between cortical growth factor production with increasing PAL. It was found that the exercised mice had increasing neurogenesis in the hippocampus-a function of VEGF (Gómez-Pinilla et al., 1998).

\section{ENTERIC GUT MICROBIOME AND NEURO-HORMONAL REGULATION}

\section{Enteric Gut Microbiome Complexity}

It is becoming increasingly more likely that complex neurohormonal regulation is crucial in the optimization of neuronal performance. This control is provided within the central nervous system and also from elements arising outside the brain, including the gut. Micro-organisms have been co-existing in the gastrointestinal tract of metazoans in a symbiotic relationship (Cho and Blaser, 2012; Mayer et al., 2015). The human intestinal tract alone consists of approximately 100 trillion $\left(10^{14}\right)$ microbes, and the gut reservoir of all extant humans is between $10^{23}$ and $10^{24}$ microbial cells (Ley et al., 2006; Table 1). Humans are not individual entities but entangled communities of cells and 
TABLE 1 | Bacterial species which produce key neuro-metabolites.

\begin{tabular}{ll}
\hline Bacteria & $\begin{array}{l}\text { Neuro-transmitter/ } \\
\text { Neuro-modulator } \\
\text { produced }\end{array}$ \\
\hline $\begin{array}{l}\text { Enterococcus spp. } \\
\text { Escherichia }\end{array}$ & Serotonin \\
Corynebacterium spp. & \\
Streptococcus spp. & \\
Bacillus spp. & Dopamine \\
Lactobacillus spp. & Acetylcholine \\
Lactobacillus spp. & $\gamma$-aminobutyric acid (GABA) \\
Bifidobacterium spp. & \\
Dobacterium & \\
Echerichia spp. & Noradrenaline \\
Bacillus spp. & \\
Saccharomyces spp. &
\end{tabular}

Data from Roshchina (2010), Barrett et al. (2012), Matur and Eraslan (2012), Lyte (2013) and Dinan et al. (2015).

microbes which maintain all body processes including human cognition (Gilbert et al., 2012; Lorimer, 2016; Nading, 2016; Rees et al., 2018).

The EGM in humans plays host to thousands of bacterial and protozoan species, thus containing 100 times more genes than their human hosts, and is a very active site for gene encoding (Ezenwa et al., 2012). For this reason, the EGM has been referred to as the meta-genome (second genome) that may be viewed as an essential organ (Zhao, 2010). Since the human enteric nervous system contains 500 million neurons (Furness, 2006), there is an ample opportunity for interactions between the gut biome and the nervous system.

\section{CNS and EGM Communication}

The ability for the EGM to communicate with the human brain via the gut-brain-enteric-microbiota-axis (GBEMA) in order to maintain symbiotic homeostasis is a crucial aspect of neurohormonal regulation and plays a pivotal role in human cognition (Rhee et al., 2009; Mayer, 2011; Carabotti et al., 2015; El Aidy et al., 2015).

A number of studies indicate that the increasing use of antibiotics since the 1970 s and 1980s may have led to a reduction of beneficial gut flora, thereby compromising digestive function and altering the production of neurotransmitters (DuPont and DuPont, 2011). Importantly, compromised EGM has recently been shown to contribute to many psychiatric and immunological disorders (i.e., asthma, arthritis, autism, Celiac disease, eczema, general allergies; Bested et al., 2013; Mawe and Hoffman, 2013). It should be noted that gut bacterial species also play an important role in neonatal brain development by modulating neurotrophins such as BDNF, thereby triggering synaptogenesis (Douglas-Escobar et al., 2013). Research in germ-free animals suggests that EGM colonization affects neural circuitry and behavior (Bercik et al., 2011; Cryan and Dinan, 2012; Davidson et al., 2018).

Other findings indicate that neonatal exposure to animals that have microbial pathogens may lead to reduced cognitive function and anxiety phenotypes (Diaz Heijtz et al., 2011; Carabotti et al., 2015; Kelly et al., 2015; Davidson et al., 2018). In another recent study, germ-free mice which had changes to their gastrointestinal bacterial colonies had lower expression of proteins PSD-95 and synaptophysin, which are involved in synaptogenesis (Diaz Heijtz et al., 2011). It has also been shown that a transplanted mouse strain of the fecal microbiome resulted in the recipient mouse exhibiting behaviors that were synonymous to the host mouse (Collins et al., 2013; Foster et al., 2016).

Alterations to the EGM may lead to intestinal dysbiosis resulting in faulty communicative pathways in the GBEMA, which in turn may contribute to disturbed central nervous system function (Diaz Heijtz et al., 2011; Cryan and Dinan, 2012; Mohajeri et al., 2018). It is interesting to note that partial removal of the vagus nerve (central to Gut-Brain communication), or vagotomy, annuls the probiotic effect of the EGM (Cryan and Dinan, 2012). This finding suggests that neurometabolites that are produced in the EGM are vagus-dependent (Cryan and Dinan, 2012).

Similarly, administration of probiotics in the form of Bifidobacteria infantis into naïve rats was associated with an attenuation of pro-inflammatory response (IFN- $\gamma$, TNF- $\alpha$ and IL- 6 cytokines) and an increase in the neurotransmitter serotonin, which is key to mood regulation and learning, and therefore, crucial to cognitive organization (Desbonnet et al., 2008). A possible reason for this could be because Bifidobacteria infantis is one of the most prolific bacterial genera within the first days to weeks of the neonate (Boesten et al., 2011; Jost et al., 2012; Underwood et al., 2015).

Indigenous strains of microbiota have also been found to modulate serotonin in the hippocampus, as well as, regulating serotonin host biosynthesis (Clarke et al., 2013; Yano et al., 2015).

\section{EGM Modulation by Vagus Nerve and Cognition}

Some researchers contend that the "microbiota-gut-vagus-brain axis" may modulate human behavior (Montiel-Castro et al., 2013; Alcock et al., 2014), while other studies note that some "subliminal interoceptive" gut inputs from microbiota may influence human affective states, memory formation, and decision-making processes (Craig, 2002; Berntson et al., 2003). Information from the gut to the vagus nerve is transmitted to the brain where it is processed in the nucleus solitarius which assists in homeostatic regulation, with other projections to the amygdala and PFC (Mohajeri et al., 2018). The amygdala is an area for microbial induced gene activity (Morgan et al., 1993; Stilling et al., 2015). Microbiotic modulation of the vagus nerve was demonstrated in mice in which the introduction of a specific gut bacterial species led to the triggering of vagus nerve dependent neuronal regions in the brain, leading to anxiety type behavior (Goehler et al., 2005; Foster et al., 2016). These findings point to neuro-hormonal regulation outside the cerebrum as a factor in affecting human cognitive abilities. It has been suggested that a reason for EGMs influence of the CNS is due to gut bacterial ability to produce neurochemicals that are structurally similar to the host's nervous system (Lyte, 2013). This bio-mimicry faculty of gut bacterial species implies that there exists a constant bidirectional communication between the EGM and host. 


\section{GI Tract Inflammation and Cognition}

Individuals with intestinal disorders are often affected by cognitive and mood disorders. For example, MRI brain imaging of children (10-14 years old) with Crohn's disease showed thinning of the posterior and middle frontal gyri, poorer cognitive and verbal memory and impaired performance (Berrill et al., 2013; Gareau, 2016; Mrakotsky et al., 2016). There has also been found a correlation between colonic inflammation and deficits in the CA1 region of the hippocampus (Novotný et al., 2019). Research studies have drawn correlations between the EGM and neurological and psychiatric disorders such as schizophrenia, multiple sclerosis, Parkinsons' disease and Alzheimer's disease (Fröhlich et al., 2016; Parashar and Udayabanu, 2016; Martin et al., 2018; Novotný et al., 2019). Inflammation of the GI tract can compromise the gut barrier function (leaky gut syndrome) and enable bacteria can pass into the systemic circulation. Such translocation of bacteria has been linked to pathophysiologies and altered cognition (Giannelli et al., 2014; Slyepchenko et al., 2017; Hegde et al., 2018; Sarkar et al., 2018).

\section{Cognition and EGM: Prenatal and Postnatal Brain Development}

Studies conducted on the microbiome in the early life stage have identified that gut bacteria takes approximately 2-3 years before it resembles the adult microbiome (Yatsunenko et al., 2012; Goyal et al., 2015; Carlson et al., 2018). Rapid neurophysiological development of neonates is accompanied by equally prompt changes of the microbiome. This concomitant growth could be important in order for the microbiome to regulate metabolic processes of the neonate brain (Al-Asmakh et al., 2012; Koren et al., 2012). The nascent influence of the microbiome has profound effects through human ontogeny. Several studies argue that gut bacteria can infiltrate the meconium, amniotic fluid and placenta (Jiménez et al., 2008; Gosalbes et al., 2013; Hansen et al., 2015; D’Argenio, 2018). The placenta may also produce serotonin (5-HT) to reach the fetus. Serotonin is important for development of the fetal forebrain (Al-Asmakh et al., 2012; Goyal et al., 2015). During fetal development, the placenta regulates fetal stress response by hormonal interacting with the hypothalamus-pituitaryadrenal (HPA) axis (Al-Asmakh et al., 2012). Rat models reveal that HPA activity in the fetus may lead to a decline in cognitive performance and elevated behavioral and anxiety response (Alonso et al., 1991; Vallée et al., 1997). Although the current understanding of prenatal development is increasing, researchers have yet to determine the microbiotic mechanisms informing the fetal brain. In the future microbial communities could be used to support fetal cognitive development (Carlson et al., 2018).

\section{Neuroendocrine System and Cognition}

At least 12 types of neuroendocrine and enteroendocrine cells (NECs) are located in the epithelial cells of the GI tract and are involved in more than 20 molecular signals (Furness et al., 2013; Martin et al., 2018). Changes in the
EGM can lead to subsequent changes to neurotransmitters and neuropeptides (Novotný et al., 2019). Various authors note that molecular neuropeptides and neurotransmitters (acetylcholine, GABA, DA, melatonin histamine) are activated by EECs (Barrett et al., 2012). The EGM modulates serotonergic pathways between the CNS and ENS which assist in learning and cognition (Mahoney et al., 2005; Forsythe et al., 2016). The importance of neuroendocrine regulated 5-HT has been the focus of several studies. One study in which mice were colonized by human fecal microbiota resulted in an increase in 5-HT tissue concentration colonic tryptophan 5-hydroxylase 1 (TPH1; Reigstad et al., 2015). Furthermore, the bacterial species Clostridia promotes the biosynthesis of 5 - HT by enterochromaffin cells (ECs; Forsythe et al., 2016). It has been speculated that EC derived 5-HT may influence EGM composition with subsequent changes in brain regulation and behavior (Forsythe et al., 2016).

\section{CONCLUSION}

The hypothesis presented here argues that brain size does not exert an influence on an individual's cognitive abilities. Even the most ardent supporters of the correlation between brain size and intelligence confirm that brain size contributes to no more than approximately $10 \%$ of the total variance in intelligence. Moreover, this level of correlation may be a result of the correlation of both variables to some third factor (e.g., body size) rather than a direct relationship. Any smallheaded, highly intelligent person (and there are millions of them) falsifies the brain size-intelligence relation hypothesis. It is well known that correlation does not prove causation. The findings of many investigations have indicated the importance of neurotransmitters in the regulation of cognitive function. $\mathrm{DA}, 5 \mathrm{HT}$, and neurotrophins have been identified as the important neurotransmitters that regulate this neurological performance. Evolutionary evidence supports the involvement of DA, 5HT and neurotrophins in the development of the human brain. Furthermore, the current use of neurotransmitter agonists or antagonists in the treatment of various conditions associated with neurotransmitter imbalances implicates neurohormonal regulation as a key factor influencing neurological performance of the brain, particularly intelligence. Drug addictions show the obvious influence of chemical regulation on brain function. In addition, neurotransmitters that are synthesized by the enteric microbiome appear to affect changes in cognitive aptitude, namely intelligence. Moreover, this article has highlighted the influential role of the EGM in informing human cognition.

Technological advancements will likely facilitate a more intricate approach to detailing the components that dictate intelligence. The evidence presented in this article suggests that the paradigm of what influences intelligence needs to be reassessed once more. It appears that the archaic practice of considering that mental fortitude is dictated by brain volume is beginning to recede. A more insightful approach, taking into account the concentration and regulation of neurotransmitters, 
as well as, the synaptic architecture of the brain is necessary if our understanding of intelligence is to advance. The potential for other, as yet unknown factors, playing a role also needs to be considered.

\section{DATA AVAILABILITY STATEMENT}

Publicly available datasets were analyzed in this study. This data can be found here: Henneberg (1988), Previc (2009), Roshchina (2010), Barrett et al. (2012), Matur and Eraslan (2012), Lyte (2013) and Dinan et al. (2015).

\section{REFERENCES}

Akil, M., Pierri, J. N., Whitehead, R. E., Edgar, C. L., Mohila, C., Sampson, A. R., et al. (1999). Lamina-specific alterations in the dopamine innervation of the prefrontal cortex in schizophrenic subjects. Am. J. Psychiatry 156, 1580-1589. doi: 10.1176/ajp.156.10.1580

Al-Asmakh, M., Anuar, F., Zadjali, F., Rafter, J., and Pettersson, S. (2012). Gut microbial communities modulating brain development and function. Gut Microbes 3, 366-373. doi: 10.4161/gmic. 21287

Alcock, J., Maley, C. C., and Aktipis, C. A. (2014). Is eating behavior manipulated by the gastrointestinal microbiota? Evolutionary pressures and potential mechanisms. BioEssays 36, 940-949. doi: 10.1002/bies.2014 00071

Alonso, J., Castellano, M. A., and Rodriguez, M. (1991). Behavioral lateralization in rats: prenatal stress effects on sex differences. Brain Res. 539, 45-50. doi: 10.1016/0006-8993(91)90684-n

Armstrong, E., and Bergeron, R. (1985). Relative brain size and metabolism in birds. Brain Behav. Evol. 26, 141-153. doi: 10.1159/000118782

Barbas, H. (2015). General cortical and special prefrontal connections: principles from structure to function. Annu. Rev. Neurosci. 38, 269-289. doi: 10.1146/annurev-neuro-071714-033936

Barrett, E., Ross, R. P., O’Toole, P. W., Fitzgerald, G. F., and Stanton, C. (2012). $\gamma$-Aminobutyric acid production by culturable bacteria from the human intestine. J. Appl. Microbiol. 113, 411-417. doi: 10.1111/j.1365-2672.2012. 05344.x

Barton, R. A., and Harvey, P. H. (2000). Mosaic evolution of brain structure in mammals. Nature 405, 1055-1058. doi: 10.1038/35016580

Barton, R. A., and Venditti, C. (2013). Human frontal lobes are not relatively large. PNAS 110, 9001-9006. doi: 10.1073/pnas.1215723110

Bercik, P., Denou, E., Collins, J., Jackson, W., Lu, J., Jury, J., et al. (2011). The intestinal microbiota affect central levels of brain-derived neurotropic factor and behavior in mice. Gastroenterology 141, 599-609. doi: 10.1053/j.gastro. 2011.04.052

Berntson, G. G., Sarter, M., and Cacioppo, J. T. (2003). Ascending visceral regulation of cortical affective information processing. Eur. J. Neurosci. 18, 2103-2109. doi: 10.1046/j.1460-9568.2003. 02967.x

Berrill, J. W., Gallacher, J., Hood, K., Green, J. T., Matthews, S. B., Campbell, A. K., et al. (2013). An observational study of cognitive function in patients with irritable bowel syndrome and inflammatory bowel disease. Neurogastroenterol. Motil. 25:e918-704. doi: 10.1111/nmo.12219

Bested, A. C., Logan, A. C., and Selhub, E. M. (2013). Intestinal microbiota, probiotics and mental health: from Metchnikoff to modern advances: part II-contemporary contextual research. Gut Pathog. 5:3. doi: 10.1186/17574749-5-3

Blinkov, S. M., and Glezer, I. I. (1968). Das Zentralnervensystem in Zahlen und Tabellen. Jena: Fischer.

Boesten, R., Schuren, F., Ben Amor, K., and Haarman, M. (2011). Bifidobacterium population analysis in the infant gut by direct mapping of genomic hybridization patterns: potential for monitoring temporal development and effects of dietary regimens. Microb. Biotechnol. 4, 417-427. doi: 10.1111/j.17517915.2010.00216.x

\section{AUTHOR CONTRIBUTIONS}

AS: substantial contributions to the conception or design of the work, drafting the work or revising it critically for important intellectual content, provide approval for publication of the content and agreed to the accuracy or integrity of the article. JG: substantial contributions to the conception or design of the work and agreed to the accuracy or integrity of the article. JK and MH: contributions to the conception or design of the work and agreed to the accuracy or integrity of the article.

Brisch, R., Saniotis, A., Wolf, R., Bielau, H., Steiner, J., Bernstein, H., et al. (2014). The role of dopamine in schizophrenia from a neurobiological and evolutionary perspective: old fashioned, but still in vogue. Front. Psychiatry 5, 1-11. doi: 10.3389/fpsyt.2014.00047

Broadhurst, C. L., Crawford, M. A., Cunnane, S. C., Parkington, J. E., and Schmidt, W. F. (2002). Brain-specific lipids from marine, lacustrine, or terrestrial food resources: potential impact on early African Homo sapiens. Comp. Biochem. Physiol. B Biochem. Mol. Biol. 131, 653-673. doi: 10.1016/s1096-4959(02)00002-7

Broca, P. (1861). Sur le volume et la forme du cerveau suivant les in-dividus et suivant les races. Bull. Mem. Soc. Anthropol. Paris 2, 139-207, 301-321, 441-446.

Brodmann, K. (1913). Neue forschungsergebnisse der grosshirnrindenanatomie mit besonderer berücksichtigung anthropologischer Fragen. Die Naturwissenschaften 1, 1120-1122 . doi: 10.1007/bf01493159

Brown, P. (1992). Recent human evolution in East Asia and Australasia. Philos. Trans. R. Soc. Lond. B Biol. Sci. 331:23542. doi: 10.1098/rstb.1992.0101

Bugnyar, T., Reber, S. A., and Buckner, C. (2016). Ravens attribute visual access to unseen competitors. Nature Commun. 7:10506. doi: 10.1038/ncomms 10506

Carabotti, M., Scirocco, A., Maselli, A., and Severi, C. (2015). The gut-brain axis: interactions between enteric microbiota, central and enteric nervous systems. Ann. Gastroenterol. 28, 203-209.

Carlson, A. L., Xia, K., Azcarate-Peril, M. A., Goldman, B. D., Ahn, M., Styner, M. A., et al. (2018). Infant gut microbiome associated with cognitive development. Biol. Psychiatry 83, 148-159. doi: 10.1016/j.biopsych.2017. 06.021

Cho, I., and Blaser, M. J. (2012). The human microbiome: at the interface of health and disease. Nat. Rev. Genet. 13, 260-270. doi: 10.1038/nrg3182

Clarke, G., Grenham, S., Scully, P., Fitzgerald, P., Moloney, R. D., Shanahan, F., et al. (2013). The microbiome-gut-brain axis during early life regulates the hippocampal serotonergic system in a sex-dependent manner. Mol. Psychiatry 18, 666-673. doi: 10.1038/mp.2012.77

Collins, S. M., Kassam, Z., and Bercik, P. (2013). The adoptive transfer of behavioral phenotype via the intestinal microbiota: experimental evidence and clinical implications. Curr. Opin. Microbiol. 16, 240-245. doi: 10.1016/j.mib. 2013.06.004

Craig, A. D. (2002). How do you feel? Interoception: the sense of the physiological condition of the body. Nat. Rev. Neurosci. 3, 655-666. doi: 10.1038/nrn894

Cryan, J. F., and Dinan, T. G. (2012). Mind-altering microorganisms: the impact of the gut microbiota on brain and behaviour. Nat. Rev. Neurosci. 13, 701-712. doi: $10.1038 / \mathrm{nrn} 3346$

Dally, J. M., Emery, N. J., and Clayton, N. S. (2006). Food-caching western scrub-jays keep track of who was watching when. Science 312, 1662-1665. doi: $10.1126 /$ science. 1126539

D'Argenio, V. (2018). The prenatal microbiome: a new player for human health. High Throughput 7:E38. doi: 10.3390/ht7040038

Darwin, C. (1871). The Descent of Man. London: Murray.

Davidson, G. L., Cooke, A. C., Johnson, C. N., and Quinn, J. L. (2018) The gut microbiome as a driver of individual variation in cognition and functional behaviour. Philos. Trans. R. Soc. Lond. B Biol. Sci. 373:20170286. doi: 10.1098/rstb.2017.0286 
De Miguel, C., and Henneberg, M. (2001). Variation in hominid brain size: how much is due to method? Homo 52, 3-58. doi: $10.1078 / 0018-442 \mathrm{x}-$ 00019

Desbonnet, L., Garrett, L., Clarke, G., Bienenstock, J., and Dinan, T. G. (2008). The probiotic Bifidobacteria infantis: an assessment of potential antidepressant properties in the rat. J. Psychiatr. Res. 43, 164-174. doi: 10.1016/j.jpsychires. 2008.03.009

Diaz Heijtz, R., Wang, S., Anuar, F., Qian, Y., Björkholm, B., Samuelsson, A., et al. (2011). Normal gut microbiota modulates brain development and behavior. Proc. Natl. Acad. Sci. U S A 108, 3047-3052. doi: 10.1073/pnas.10105 29108

Dicke, U., and Roth, G. (2016). Neuronal factors determining high intelligence. Philos. Trans. R. Soc. Lond. B Biol. Sci. 371:20150180. doi: 10.1098/rstb. 2015.0180

Dinan, T. G., Stilling, R. M., Stanton, C., and Cryan, J. F. (2015). Collective unconscious: how gut microbes shape human behaviour. J. Psychiatr. Res. 63, 1-9. doi: 10.1016/j.jpsychires.2015.02.021

Douglas-Escobar, M., Elliott, E., and Neu, J. (2013). Effect of intestinal microbial ecology on the developing brain. JAMA Pediatr. 167, 374-379. doi: 10.1001/jamapediatrics.2013.497

DuPont, A. W., and DuPont, H. L. (2011). The intestinal microbiota and chronic disorders of the gut. Nat. Rev. Gastroenterol. Hepatol. 8, 523-531. doi: $10.1038 /$ nrgastro.2011.133

El Aidy, S., Dinan, T. G., and Cryan, J. F. (2015). Gut microbiota: the conductor in the orchestra of immune neuroendocrine communication. Clin. Ther. 37, 954-967. doi: 10.1016/j.clinthera.2015.03.002

Elston, G. N. (2003). Cortex, cognition and the cell: new insights into the pyramidal neuron and prefrontal function. Cereb. Cortex 13, 1124-1138. doi: 10.1093/cercor/bhg093

Elston, G. N., Benavides-Piccione, R., Elston, A., Manger, P. R., and Defelipe, J. (2011). Pyramidal cells in prefrontal cortex of primates: marked differences in neuronal structure among species. Front. Neuroanat. 5:2. doi: 10.3389/fnana. 2011.00002

Elston, G. N., Benavides-Piccione, R., Elston, A., Zietsch, B., Defelipe, J., Manger, P., et al. (2006). Specializations of the granular prefrontal cortex of primates: implications for cognitive processing. Anat. Rec 288, 26-35. doi: 10.1002/ar.a.20278

Elston, G. N., and Garey, L. J. (2009). "Prefrontal cortex: brodmann and cajal revisited," in Prefrontal Cortex: Roles, Interventions and Traumas, eds L. LoGrasso and G. Morretti (New York, NY: Nova), 245-259.

Emery, N. J., and Clayton, N. S. (2001). Effects of experience and social context on prospective caching strategies by scrub jays. Nature 414, 443-446. doi: $10.1038 / 35106560$

Emery, N. J., and Clayton, N. S. (2005). Evolution of the avian brain and intelligence. Curr. Biol. 15, R946-950. doi: 10.1016/j.cub.2005.11.029

Ezenwa, V. O., Gerardo, N. M., Inouye, D. W., Medina, M., and Xavier, J. B. (2012). Animal behaviour and the microbiome. Science 338, 198-199. doi: 10.1126/science.1227412

Font, E., García-Roa, R., Pincheira-Donoso, D., and Carazo, P. (2019). Rethinking the effects of body size on the study of brain size evolution. Brain Behav. Evol. 93, 182-195. doi: 10.1159/000501161

Forsythe, P., Kunze, P. W., and Bienenstock, J. (2016). Moody microbes or fecal phrenology: what do we know about the microbiota-gut-brain axis? BMC Med. 14:58. doi: 10.1186/s12916-016-0604-8

Foster, J. A., Lyte, M., Meyer, E., and Cryan, J. F. (2016). Gut microbiota and brain function: an evolving field in neuroscience. Int. J. Neuropsychopharmacol. 19:pyv114. doi: 10.1093/ijnp/pyv114

Fröhlich, E. E., Farzi, A., Mayerhofer, R., Reichmann, F., Jačan, A., Wagner, B., et al. (2016). Cognitive impairment by antibiotic-induced gut dysbiosis: analysis of gut microbiota-brain communication. Brain Behav. Immun. 56, 140-155. doi: 10.1016/j.bbi.2016.02.020

Furness, J. B. (2006). The Enteric Nervous System. Malden, MA: Blackwell Publishing.

Furness, J. B., Rivera, L. R., Cho, H. J., Bravo, D. M., and Callaghan, B. (2013). The gut as a sensory organ. Nat. Rev. Gastroenterol. Hepatol. 10, 729-740. doi: $10.1038 /$ nrgastro.2013.180

Fuster, J. M. (2001). Neuropsychiatric the prefrontal cortex-an update: time is of the essence. Neuron 30, 319-333. doi: 10.1016/s0896-6273(01)00285-9
Gagneux, P., Arness, B., Diaz, S., Moore, S., Patel, T., Dillmann, W., et al. (2001). Proteomic comparison of human and great ape blood plasma reveals conserved glycosylation and differences in thyroid hormone metabolism. Am. J. Phys. Anthropol. 115, 99-109. doi: 10.1002/ajpa.1061

Galton, F. (1888). Head growth in students at the University of Cambridge. Nature 40:318. doi: 10.1038/040318a0

Gao, W. J., and Zheng, Z. H. (2004). Target-specific differences in somatodendritic morphology of layer V pyramidal neurons in rat motor cortex. J. Comp. Neurol. 476, 174-185. doi: 10.1002/cne.20224

Gareau, M. G. (2016). Cognitive function and the microbiome. Int. Rev. Neurobiol. 131, 227-241. doi: 10.1016/bs.irn.2016.08.001

Geary, D. C. (2005). The Origin of Mind: Evolution of Brain, Cognition and General Intelligence. Washignton, DC: American Psychological Association.

Giannelli, V., Di Gregorio, V., Iebba, V., Giusto, M., Schippa, S., Merli, M., et al. (2014). Microbiota and the gut-liver axis: bacterial translocation, inflammation and infection in cirrhosis. World J. Gastroenterol. 20, 16795-16810. doi: 10.3748/wjg.v20.i45.16795

Gilbert, S. F., Sapp, J., and Tauber, A. I. (2012). A symbiotic view of life: we have never been individuals. Q. Rev. Biol. 87, 325-341. doi: 10.1086/668166

Goehler, L. E., Gaykema, R. P., Opitz, N., Reddaway, R., Badr, N., and Lyte, M. (2005). Activation in vagal afferents and central autonomic pathways: early responses to intestinal infection with Campylobacter jejuni. Brain Behav. Immun. 19, 334-344. doi: 10.1016/j.bbi.2004.09.002

Gómez-Pinilla, F., So, V., and Kesslak, J. P. (1998). Spatial learning and physical activity contribute to the induction of fibroblast growth factor: neural substrates for increased cognition associated with exercise. Neuroscience 85, 53-61. doi: 10.1016/s0306-4522(97)00576-9

Gosalbes, M. J., Llop, S., Vallès, Y., Moya, A., Ballester, F., and Francino, M. P. (2013). Meconium microbiota types dominated by lactic acid or enteric bacteria are differentially associated with maternal eczema and respiratory problems in infants. Clin. Exp. Allergy 43, 198-211. doi: 10.1111/cea.12063

Gould, S. J. (1996). The Mismeasure of Man. New York, NY: WW Norton and Company.

Goyal, M. S., Venkatesh, S., Milbrandt, J., Gordon, J. I., and Raichle, M. E. (2015). Feeding the brain and nurturing the mind: linking nutrition and the gut microbiota to brain development. Proc. Natl. Acad. Sci. U S A 112, 14105-14112. doi: 10.1073/pnas.1511465112

Güntürkün, O. (2014). Is dolphin cognition special? Brain Behav. Evol. 83, 177-180. doi: 10.1159/000357551

Hansen, R., Scott, K. P., Khan, S., Martin, J. C., Berry, S. H., Stevenson, M., et al. (2015). First-pass meconium samples from healthy term vaginallydelivered neonates: an analysis of the microbiota. PLoS One 10:e0133320. doi: 10.1371/journal.pone.0133320

Haug, H. (1987). Brain sizes, surfaces and neuronal sizes of the cortex cerebri: a stereological investigation of man and his variability and a comparison with some mammals (primates, whales, marsupials, insectivores and one elephant). Am. J. Anat. 180, 126-142. doi: 10.1002/aja.1001800203

Hegde, S., Lin, Y., Golovko, G., Khanipov, K., Cong, Y., Savidge, T., et al. (2018). Microbiota dysbiosis and its pathophysiological significance in bowel obstruction. Nature 8:13044. doi: 10.1038/s41598-018-31033-0

Henneberg, M. (1988). Decrease of human skull size in the Holocene. Hum. Biol. 60, 395-405.

Henneberg, M. (1998). Evolution of the human brain: is bigger better? Clin. Exp. Pharmacol. Physiol. 25, 745-749. doi: 10.1111/j.1440-1681.1998.tb02289.x

Henneberg, M., Budnik, A., Pezacka, M., and Puch, A. E. (1985). Head size, body size and intelligence: intraspecific correlations in Homo sapiens. Homo 36, 207-218.

Henneberg, M., and Saniotis, A. (2009). Evolutionary origins of human brain and spirituality. Anthropol. Anz. 67, 427-438. doi: 10.1127/0003-5548/2009/0032

Henneberg, M., and Steyn, M. (1993). Trends in cranial capacity and cranial index in Subsaharan Africa during the Holocene. Am. J. Hum. Biol. 5, 473-479. doi: 10.1002/ajhb.1310050411

Hoffmann, M. (2013). The human frontal lobes and frontal network systems: an evolutionary, clinical and treatment perspective. ISRN Neurol. 2013:892459. doi: 10.1155/2013/892459

Inoue, S., and Matsuzawa, T. (2007). Working memory of numerals in chimpanzees. Curr. Biol. 17, R1004-R1005. doi: 10.1016/j.cub.2007. 10.027 
Jerison, H. (2001). "Epilogue: the study of primate brain evolution: where do we go from here?" in Evolutionary Anatomy of the Primate Cerebral Cortex, eds D. Falk, and K. R. Gibson (Cambridge: Cambridge University Press), 305-335.

Jerison, H. J. (1973). The Evolution of the Brain and Intelligence. New York, NY: Academic Press.

Jiménez, E., Marìn, M. L., Martìn, R., Odriozola, J. M., Olivares, M., Xaus, J., et al. (2008). Is meconium from healthy newborns actually sterile? Res. Microbiol. 159, 187-193. doi: 10.1016/j.resmic.2007.12.007

Jost, T., Lacroix, C., Braegger, C. P., and Chassard, C. (2012). New insights in gut microbiota establishment in healthy breast fed neonates. PLoS One 7:e44595. doi: 10.1371/journal.pone.0044595

Kabadayi, C., Taylor, L. A., von Bayern, A. M. P., and Osvath, M. (2016). Ravens, new caledonian crows and jackdaws parallel great apes in motor self-regulation despite smaller brains. R. Soc. Open Sci. 3:160104. doi: 10.1098/rsos.160104

Kasper, E. M., Larkman, A. U., Lubke, J., and Blakemore, C. (1994). Pyramidal neurons in layer 5 of the rat visual cortex: I. Correlation among cell morphology, intrinsic electrophysiological properties and axon targets. J. Comp. Neurol. 339, 459-474. doi: 10.1002/cne.903390402

Kelly, J. R., Kennedy, P. J., Cryan, J. F., Dinan, T. G., Clarke, G., and Hyland, N. P. (2015). Breaking down the barriers: the gut microbiome, intestinal permeability and stress-related psychiatric disorders. Front. Cell. Neurosci. 9:392. doi: 10.3389/fncel.2015.00392

Kolb, B., and Tees, C. (Eds) (2000). "The rat as a model of cortical function," in The Cerebral Cortex of the Rat (Cambridge, MA: MIT Press), 3-17.

Koren, O., Goodrich, J. K., Cullender, T. C., Spor, A., Laitinen, K., Bäckhed, H. K., et al. (2012). Host remodeling of the gut microbiome and metabolic changes during pregnancy. Cell 150, 470-480. doi: 10.1016/j.cell.2012.07.008

Lefebvre, L. (2012). Primate encephalization. Prog. Brain Res 195, 393-412. doi: 10.1016/b978-0-444-53860-4.00019-2

Lefebvre, L. (2013). Brains, innovations, tools and cultural transmission in birds, non-human primates and fossil hominins. Front. Hum. Neurosci. 7:245. doi: 10.3389/fnhum.2013.00245

Ley, R. E., Peterson, D. A., and Gordon, J. I. (2006). Ecological and evolutionary forces shaping microbial diversity in the human intestine. Cell 124, 837-848. doi: 10.1016/j.cell.2006.02.017

Lorimer, J. (2016). Gut buddies: multispecies studies and the microbiome. Environ. Humanit. 8, 57-76. doi: 10.1215/22011919-3527722

Luebke, J. I. (2017). Pyramidal neurons are not generalizable building blocks of cortical networks. Front. Neuroanat. 11:11. doi: 10.3389/fnana.2017.00011

Lyte, M. (2013). Microbial endocrinology in the microbiome-gut-brain axis: how bacterial production and utilization of neurochemicals influence behavior. PLoS Pathog. 29:e1003726. doi: 10.1371/journal.ppat.1003726

Mahoney, C., Taylor, H., and Kanarek, R. (2005). "The acute effects of meals on cognitive performance," in Nutritional Neuroscience, eds L. R. Kanarek and C. H. Prasad (Boca Raton, FL: CRC Press), 73-91.

Manger, P. R. (2013). Questioning the interpretations of behavioral observations of cetaceans: is there really support for a special intellectual status for this mammalian order? Neuroscience 250, 664-696. doi: 10.1016/j.neuroscience. 2013.07.041

Marean, C. W., Bar-Matthews, M., Bernatchez, J., Fisher, E., Goldberg, P., Herries, A. I., et al. (2007). Early human use of marine resources and pigment in South Africa during the middle pleistocene. Nature 499, 905-908. doi: 10.1038/nature06204

Mathias, R. A., Fu, W., Akey, J. M., Ainsworth, H. C., Torgerson, D. G., Ruczinski, I., et al. (2012). Adaptive evolution of the FADS gene cluster within Africa. PLoS One 7:e44926. doi: 10.1371/journal.pone.0044926

Martin, C. R., Osadchiy, V., Kalani, A., and Mayer, E. A. (2018). The brain-gutmicrobiome axis. Cell. Mol. Gastroenterol. Hepatol. 6, 133-148. doi: 10.1016/j. jcmgh.2018.04.003

Mattson, M. P. (2012). Evolutionary aspects of human exercise-born to run purposefully. Ageing Res. Rev. 11, 347-352. doi: 10.1016/j.arr.2012.01.007

Matur, E., and Eraslan, E. (2012). "The impact of probiotics on the gastrointestinal physiology," in New Advances in the Basic and Clinical Gastroenterology, ed. T. Brzozowski (Intechopen.com), 51-74.

Mawe, G. M., and Hoffman, J. M. (2013). Serotonin signalling in the gut-functions, dysfunctions and therapeutic targets. Nat. Rev. Gastroenterol. Hepatol. 10, 473-486. doi: 10.1038/nrgastro.2013.105
Mayer, E. A. (2011). Gut feelings: the emerging biology of gut-brain communication. Nat. Rev. Neurosci. 12, 453-466. doi: 10.1038/nrn3071

Mayer, E. A., Tillisch, K., and Gupta, A. (2015). Gut/brain axis and the microbiota. J. Clin. Invest 125, 926-938. doi: 10.1172/JCI76304

McBride, T., Arnold, S. E., and Gur, R. C. (1999). A comparative volumetric analysis of the prefrontal cortex in human and baboon MRI. Brain Behav. Evol. 54, 159-166. doi: 10.1159/000006620

Mohajeri, M. H., La Fata, G., Steinert, R. E., and Weber, P. (2018). Relationship between the gut microbiome and brain function. Nutr. Rev. 76, 481-496. doi: 10.1093/nutrit/nuy009

Montiel-Castro, A. J., González-Cervantes, R. M., Bravo-Ruiseco, G., and PachecoLópez, G. (2013). The microbiota-gut-brain axis: neurobehavioral correlates, health and sociality. Front. Integr. Neurosci. 7:70. doi: 10.3389/fnint.2013.00070

Morgan, M. A., Romanski, L. M., and LeDoux, J. E. (1993). Extinction of emotional learning: contribution of medial prefrontal cortex. Neurosci. Lett. 163, 109-113. doi: 10.1016/0304-3940(93)90241-c

Morton, S. G. (1849). Observations on the size of the brain in various races and families of man. Proc. Acad. Nat. Sci. Phila. 4, 221-224. doi: 10.5962/bhl.title. 118071

Mrakotsky, C., Anand, R., Watson, C., Vu, C., Matos, A., Friel, S., et al. (2016). O-018 new evidence for structural brain differences in pediatric Crohn's disease: impact of underlying disease factors. Inflamm. Bowel Dis. 22, S6-S7. doi: 10.1097/01.mib.0000480115.50061.db

Nading, A. (2016). Evidentiary symbiosis: on paraethnography in human-microbe relations. Sci. Cult. 25, 560-581. doi: 10.1080/09505431.2016.1202226

Navarrete, A., van Schaik, C. P., and Isler, K. (2011). Energetics and the evolution of human brain size. Nature 480, 91-93. doi: 10.1038/nature10629

Noakes, T., and Spedding, M. (2012). Olympics: run for your life. Nature 487, 295-296. doi: 10.1038/487295a

Novotný, M., Klimova, B., and Valis, M. (2019). Microbiome and cognitive impairment: can any diets influence learning processes in a positive way? Front. Aging Neurosci. 11:170. doi: 10.3389/fnagi.2019.00170

Olivier, G., Saussé, R., and Tissier, H. (1970). II.-Influence du milieu socioprofessionnel. Bull. Mem. Soc. Anthropol. Paris 6, 189-210. doi: 10.3406/bmsap. 1970.2194

Olney, D., Saniotis, A., and Henneberg, M. (2015). Resource management and the development of "Homo": the long march toward farming. Anthropos 2, 563-572. doi: 10.5771/0257-9774-2015-2-563

Parashar, A., and Udayabanu, M. (2016). Gut microbiota regulates key modulators of social behavior. Eur. Neuropsychopharmacol. 26, 78-91. doi: 10.1016/j. euroneuro.2015.11.002

Passingham, R. E. (1973). Anatomical differences between the neocortex of man and other primates. Brain Behav. Evol. 7, 337-359. doi: 10.1159/000124422

Passingham, R. E., and Smaers, J. B. (2014). Is the prefrontal cortex especially enlarged in the human brain? allometric relations and remapping factors. Brain Behav. Evol. 84, 156-166. doi: 10.1159/000365183

Previc, F. H. (1999). Dopamine and the origins of human intelligence. Brain Cogn. 41, 299-350. doi: 10.1006/brcg.1999.1129

Previc, F. H. (2002). Thyroid hormone production in chimpanzees and humans: implications for the origins of human intelligence. Am. J. Phys. Anthropol. 118, 402-403. doi: 10.1002/ajpa.10095

Previc, F. H. (2009). The Dopaminergic Mind in Human Evolution and History. Cambridge: Cambridge University Press.

Raghanti, M. A., Hof, P. R., and Sherwood, C. C. (2010). "The evolution of cortical neurotransmitter systems among primates and their relevance to cognition," in The Human Brain Evolving: Paleoneurological Studies in Honor of Ralph, eds D. Yuan, M. Schick, and N. Toth (Gosport, IN: Stone Age Institute Press), 195-212.

Raghanti, M. A., Stimpson, C. D., Marcinkiewiczc, J. L., Erwind, J. M., Hofe, P. R., and Sherwood, C. C. (2008). Cortical dopaminergic innervation among humans, chimpanzees, and macaque monkeys: A comparative study. Neuroscience 155, 203-220. doi: 10.1016/j.neuroscience.2008.05.008

Raichlen, D. A., and Polk, J. D. (2013). Linking brains and brawn: exercise and the evolution of human neurobiology. Proc. Biol. Sci. 280:20122250. doi: $10.1098 / \mathrm{rspb} .2012 .2250$

Rees, T., Bosch, T., and Douglas, A. E. (2018). How the microbiome challenges our concept of self. PLoS Biol. 16:e2005358. doi: 10.1371/journal.pbio.20 05358 
Reigstad, C. S., Salmonson, C. E., Rainey, J. F. III., Szurszewski, J. H., Linden, D. R., Sonnenburg, J. L., et al. (2015). Gut microbes promote colonic serotonin production through an effect of short-chain fatty acids on enterochromaffin cells. FASEB J. 29, 1395-1403. doi: 10.1096/fj.14-259598

Rhee, S. H., Pothoulakis, C., and Mayer, E. A. (2009). Principles and clinical implications of the brain-gut-enteric microbiota axis. Nat. Rev. Gastroenterol. Hepatol. 6, 306-314. doi: 10.1038/nrgastro.2009.35

Roelands, B., and Meeusen, R. (2010). Alterations in central fatigue by pharmacological manipulations of neurotransmitters in normal and high ambient temperature. Sports Med. 40, 229-246. doi: 10.2165/11533670000000000-00000

Roshchina, V. V. (2010). "Evolutionary considerations of neurotransmitters in microbial, plant and animal cells," in Microbial Endocrinology, Interkingdom Signaling in Infectious Disease and Health, eds M. Lyte and P. P. E. Freestone (Berlin: Springer Science+Business Media, LLC), 17-52. doi: 10.1007/978-14419-5576-0_2

Roth, G. (2013). The Long Evolution of Brains and Minds. Dordrecht, Netherlands: Springer.

Ruff, C. B., Trinkaus, E., and Holliday, T. W. (1997). Body mass and encephalisation in Pleistocene Homo. Nature 387, 173-176. doi: 10.1038/ $387173 \mathrm{a} 0$

Rushton, P. J., and Ankney, D. C. (1996). Brain size and cognitive ability: correlations with age, sex, social class, arid race. Psychon. Bull. Rev. 3, 21-36. doi: 10.3758/BF03210739

Saniotis, A., and Henneberg, M. (2013a). Conceptual challenges to evolutionary biology: a necessary step. Biocosmology Neo-Aristotelism 3, 7-16.

Saniotis, A., and Henneberg, M. (2013b). Evolutionary medicine and future humanity: will evolution have the final word? Humanities 2, 278-291. doi: $10.3390 / \mathrm{h} 2020278$

Saniotis, A., and Henneberg, M. (2011). Medicine could be constructing human bodies in the future. Med. Hypotheses 77, 560-564. doi: 10.1016/j.mehy.2011.06.031

Saniotis, A., Henneberg, M., Kumaratilake, J., and Grantham, J. P. (2014). Messing with the mind: evolutionary challenges to human brain augmentation. Front. Syst. Neurosci. 8:152. doi: 10.3389/fnsys.2014.00152

Sarkar, A., Harty, S., Lehto, S. M., Moeller, A. H., Dinan, T. G., Dunbar, R. I. M., et al. (2018). The microbiome in psychology and cognitive neuroscience. Trends Cogn. Sci. 22, 611-636. doi: 10.1016/j.tics.2018.04.006

Semendeferi, K., Lu, A., Schenker, N., and Damasio, H. (2002). Humans and great apes share a large frontal cortex. Nat. Neurosci. 5, 272-276. doi: 10.1038/ nn814

Sherwood, C. C., Holloway, R. L., Semendeferi, K., and Hof, P. R. (2005). Is prefrontal white matter enlargement a human evolutionary specialization? Nat. Neurosci. 8, 537-538. doi: 10.1038/nn0505-537

Slyepchenko, A., Maes, M., Jacka, F. N., Köhler, C. A., Barichello, T., McIntyre, R. S., et al. (2017). Gut microbiota, bacterial translocation and interactions with diet: pathophysiological links between major depressive disorder and non-communicable medical comorbidities. Psychother. Psychosom. 86, 31-46. doi: 10.1159/000448957

Smaers, J. B., Steelea, J., Caseb, C. R., Cowper, A., Amunts, K., and Zilles, K. (2011). Primate prefrontal cortex evolution: human brains are the extreme of a lateralized ape trend. Brain Behav. Evol. 77, 67-78. doi: 10.1159/0003 23671

Spruston, N. (2008). Pyramidal neurons: dendritic structure and synaptic integration. Nat. Rev. Neurosci. 9, 206-221. doi: 10.1038/nrn2286

Stilling, R. M., Ryan, F. J., Hoban, A. E., Shanahan, F., Clarke, G., Claesson, M., et al. (2015). Microbes and neurodevelopment-absence of microbiota during early life increases activity-related transcriptional pathways in the amygdala. Brain Behav. Immun. 50, 209-220. doi: 10.1016/j.bbi.2015. 07.009

Tan, U., Tan, M., Polat, P., Ceylan, Y., Suma, S., and Okur, A. (1999). Magnetic resonance imaging brain size/IQ relations in Turkish university students. Intelligence 27, 83-92. doi: 10.1016/s0160-2896(99)00015-x

Underwood, M. A., German, J. B., Lebrilla, C. B., and Mills, D. A. (2015). Bifidobacterium longum subspecies infantis: champion colonizer of the infant gut. Pediatr. Res. 77, 229-235. doi: 10.1038/pr.2014.156

Vallée, M., Mayo, W., Dellu, F., Le Moal, M., Simon, H., and Maccari, S. (1997). Prenatal stress induces high anxiety and postnatal handling induces low anxiety in adult offspring: correlation with stress-induced corticosterone secretion. J. Neurosci. 17, 2626-2636. doi: 10.1523/jneurosci.17-0702626.1997

Walter, R. C., Buffler, R. T., Bruggemann, J. H., Guillaume, M. M., Berhe, S. M., Negassi, B., et al. (2000). Early human occupation of the Red Sea coast of Eritrea during the last interglacial. Nature 405, 65-69. doi: 10.1038/3511048

Yano, J. M., Yu, K., Donaldson, G. P., Shastri, G. G., Ann, P., Ma, L., et al. (2015). Indigenous bacteria from the gut microbiota regulate host serotonin biosynthesis. Cell 161, 264-276. doi: 10.1016/j.cell.2015.02.047

Yatsunenko, T., Rey, F. E., Manary, M. J., Trehan, I., Dominguez-Bello, M. G., Contreras, M., et al. (2012). Human gut microbiome viewed across age and geography. Nature 486, 222-227. doi: 10.1038/nature11053

Zhao, L. (2010). The tale of our other genome. Nature 465, 879-880. doi: $10.1038 / 465879$ a

Conflict of Interest: The authors declare that the research was conducted in the absence of any commercial or financial relationships that could be construed as a potential conflict of interest.

Copyright (C) 2020 Saniotis, Grantham, Kumaratilake and Henneberg. This is an open-access article distributed under the terms of the Creative Commons Attribution License (CC BY). The use, distribution or reproduction in other forums is permitted, provided the original author(s) and the copyright owner(s) are credited and that the original publication in this journal is cited, in accordance with accepted academic practice. No use, distribution or reproduction is permitted which does not comply with these terms. 